\title{
Study on Necessity and Significance of Nationalization in Piano Education
}

\author{
Lu Yuan \\ College of Music, Yuxi Normal University, Yunnan, China, 653100
}

Keywords: piano education; nationalization; necessity; ways and measures

Abstract: The piano is an art originated from the West. In recent years, thanks to the nationalization of piano creation and performance, the nationalization process of this foreign art has been greatly promoted. In the next step, we need to focus on the development of nationalized piano education, so that the Chinese piano can continue to move in a three-dimensional direction along the nationalization. In view of this, this paper starts from the necessity of the nationalization of piano education and analyzes the specific ways and measures.

\section{Introduction}

In addition to the various changes within the teaching, the development of the nationalized piano education in colleges and universities requires a good external environment to form a corresponding cooperation and interaction, which creates a good development atmosphere. It is necessary to strengthen the intensity of Chinese piano publishing and publicity. It is necessary to encourage publishing units, media, etc., to put the promotion and popularization of Chinese piano works in the first place, and to guide creators to create more excellent works. Only with rich and excellent works, the nationalization process of piano education can be obtained. Constant motivation.

\section{The necessity and significance of the nationalization of piano education}

The driving force of the nationalization of piano education is the same as the nationalization of piano creation. It is also the result of the promotion of national thought. The famous Chinese artists such as Ding Shande and Zhou Guangren have created a large number of piano nationalized works. They are all music. The teachers of the college, while promoting the nationalization of the piano, are convenient to pass on their ideas to their students. Therefore, the nationalization of piano education is not only a way to spread the nationalization of piano, but also an important embodiment of the nationalization of piano. The nationalization of piano education is not only influenced and promoted by national thought, but also related to the increasing status of mother-tongue music education. The piano music education is changed to the mother tongue, which is also the biggest feature of the nationalization of piano education. In the twentieth century, there was a "Chinese music backwardness" issue that caused heated debate in the academic world. To this end, China's music education community has put forward the concept of "music education with Chinese culture as its mother tongue". Because "the traditional music of a nation must rely on a 
specific language and language of the nation to communicate, record and spread, especially the traditional instrumental music without the literary attachments, and the folks still mainly adopt the method of 'spoken heart' to inherit." The best language for learning and research is the mother tongue. In addition, the mother tongue music education system established in Chinese culture helps to get rid of the influence of Western industrial civilization values and music education values, and establish the musical education values that are suitable for the needs of China's cultural construction [1].

\subsection{The needs of Chinese piano development}

The piano is an external art. If you want to survive and develop in a new environment, you must experience the development of nationalization, including the nationalization of creation, performance, education and many other aspects. From the reality, in the course of a hundred years of development, the nationalization of piano creation and performance has achieved certain achievements. An important performance is the birth of a large number of outstanding Chinese piano works and the success of many Chinese performers on the international stage. Compared with the two aspects of creation and performance, the nationalization of piano education has not been fully paid attention to, especially as the main front of Chinese piano talent training - colleges and universities, but also did not establish a relevant understanding, which makes the whole The development of the nationalization process has been greatly affected. Therefore, we must strengthen and improve this link in order to better promote the overall development of Chinese piano nationalization [2].

\subsection{The development needs of the world piano art}

Since its birth, the piano has become an instrumental art that is widely recognized and loved by all parts of the world and through various developments and improvements. It is also the development and innovation of the creation, performance and education of all regions and ethnic groups that have jointly built the world of piano art and the glory of a hundred schools of thought. China is a big country with great influence in the world, and it is also the country with the largest number of piano learners and practitioners. Adhering to the development direction of nationalization, in addition to promoting the development of the Chinese piano industry, it can make its own contribution to the world of piano art, reflecting the responsibility and demeanor of a piano power.

\subsection{The development needs of piano learners}

From the personal perspective of learners, the formation of personal artistic style should be an important learning goal, and how can we form a personal artistic style? An effective channel is the persistence and expression of nationality. Throughout the process of learning and expression, many new insights and thoughts can be formed to form a distinctive performance. Many countries and regions with developed piano art in the world have formed piano schools, such as the German and Austrian piano school, the French piano school, the Russian piano school, etc., and the formation of this school is obviously also nationalized and personalized. based on. Therefore, no matter from the development of individuals or the whole, the implementation of nationalized piano education has long been imperative [3]. 


\section{Development Measures and Ways of Nationalization of Piano Education in Colleges and Universities}

\subsection{Establish a sense of development}

The formation of correct consciousness and ideas is undoubtedly the foundation of a career development. In order to promote the development of nationalization of piano education, we must first establish a correct consciousness and concept, including piano art workers, piano teachers and piano learners. Take the most popular piano examinations as an example. From the current repertoire, the proportion of Chinese piano works is seriously out of balance, and it is almost the world of Western works. If you can add more Chinese piano works and make some adjustments in the evaluation criteria, you can play a positive guiding role. Piano teachers are the leaders of the entire piano teaching activities. Their cognition and attention to nationalization have a decisive influence on students. Therefore, teachers need to truly recognize the value and significance of nationalization, and form good demonstrations and driving actions with their own practical actions. They use the influence of the role of teacher identity to guide students to form corresponding understandings, and are willing and good at playing Chinese piano works. This is also a successful experience. For example, the famous pianist Mr. Fu Cong has always insisted on using nationalized thinking to understand and express Western piano works. Therefore, his performance is different and widely recognized. Only the piano workers, piano teachers, and piano learners can work together to make the nationalization of piano education advance [4]. Analysis of the nationalization teaching mode as shown below.

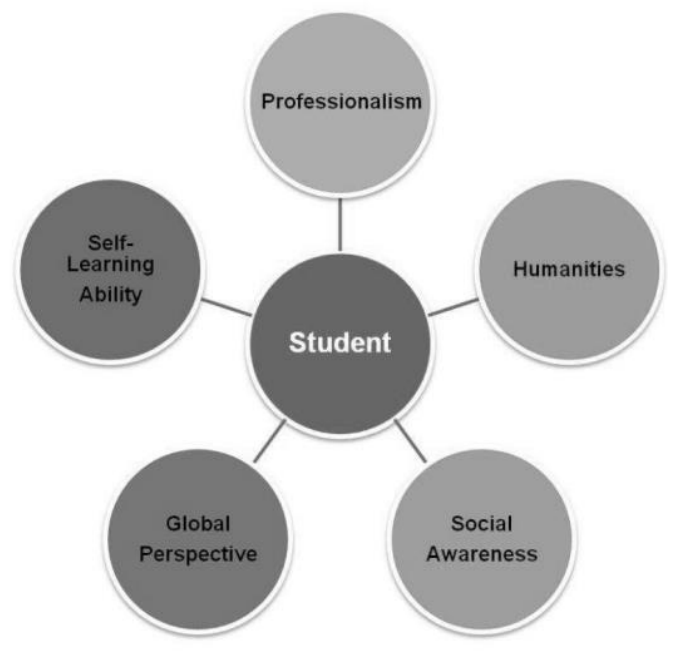

Fig.1 Analysis of the nationalization teaching mode

\subsection{Improve the structure of teaching materials}

The textbook is directly related to the question of "teaching what" and "what to learn" and is in a fundamental position throughout the teaching process. The reason why Western piano art has achieved great development achievements is based on scientific and rich textbooks. For the nationalization of piano education in colleges and universities, we must first sort out and classify the existing content, and secondly, we should improve and supplement it on this basis. In terms of combing and sorting, it is necessary to classify the current works according to different standards, such as different performance contents, expression forms, and grade standards, and lay a foundation for its extensive and extensive application. In terms of enrichment and perfection, although in the 
course of one hundred years of development, Chinese piano works are already very rich, but they are characterized by systematic and targeted lacking, which is significantly different from the developed countries in the West. For example, the famous Hungarian musician Bartok has written two collections of "Little Universe" and "Dedicated to Children" for children. He hopes that the performers will establish a national consciousness at the beginning of piano learning. In contrast, the number of Chinese piano works has been changed. In recent years, some works have distinct individualized colors. Therefore, they have been restricted in terms of popularization and scale, and should be supplemented and improved as soon as possible[5].

\subsection{Develop curriculum standards}

Judging from the actual situation at present, the piano teaching in colleges and universities is mainly based on Western piano works, and the corresponding curriculum and evaluation criteria are formed, which is obviously not conducive to the national development of the piano. Therefore, in addition to the improvement of the textbook structure, it should be strengthened from the following two aspects: First, the technical standards for nationalized works. Nikotz of the Russian piano school once said: "What kind of piano music, what kind of piano playing skills." So while emphasizing the number and type of Chinese piano works, it should also form technical standards. The development of this standard is not a constraint on the performers, but a reference and reference, so that their performance can be both disciplined and distinguishable from the performance of Western works. The second is to open a skills training course with national characteristics. Under the influence of history and many other reasons, the courses of harmony, polyphony and composition in the current music majors are all Westernized, so the students' concept of sound, creation and performance are also seriously westernized. Actively try to open some Chinese-style skills training courses, such as accompaniment for national instrumental music, and the original ecological folk songs, thus enhancing and enriching students' national consciousness. The development stage of the nationalized teaching mode is as follows.

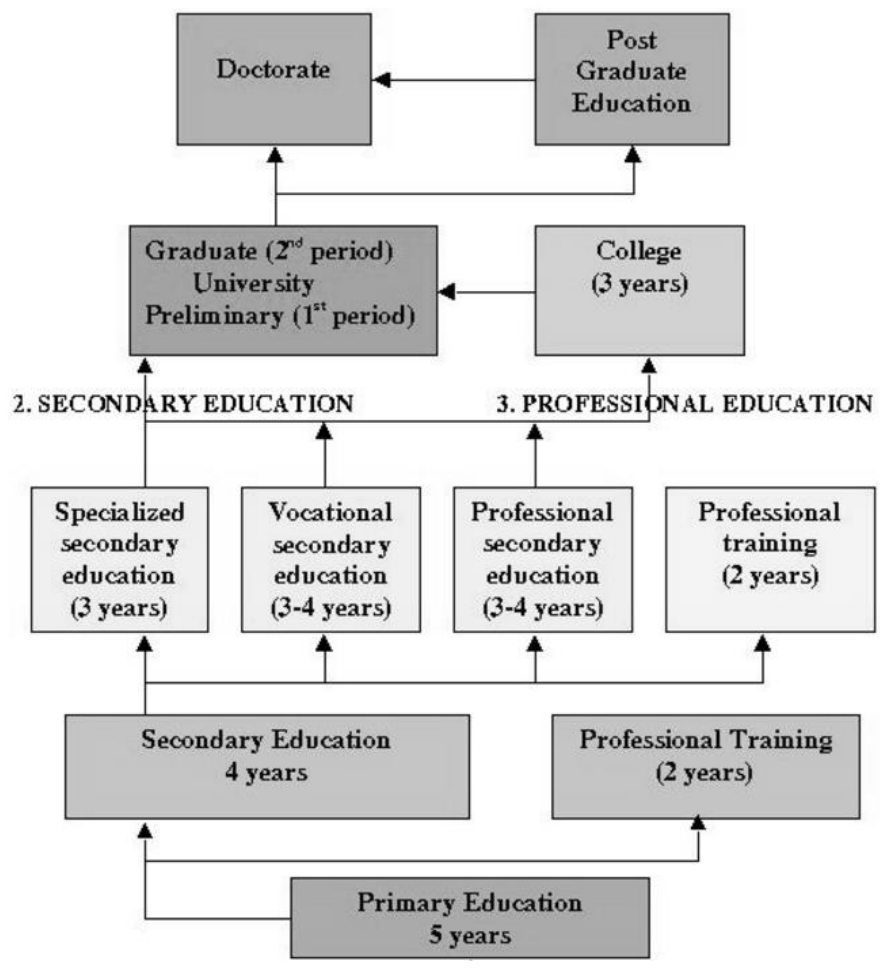

Fig.2 Evelopment stage of the nationalized teaching mode 


\subsection{Optimizing the external environment}

To carry out various forms of activities. Various forms of performance, appreciation, seminars and other activities can enable practitioners and learners to feel a strong national atmosphere and enhance their national aesthetic awareness and level. Moreover, in the development of China's piano industry in the direction of popularization, it is necessary to form some fixed and authoritative activities, making it the base and link for the development of Chinese piano nationalization and becoming an important part of the national music culture life. Strengthen dialogue and exchanges between China and the world. As early as 1982, the American and Chinese Art Exchange Center organized a Chinese violin teacher to visit the United States. A series of seminars were held on "Liang Zhu", and musicians from both China and the United States benefited a lot. Today, the exchanges between countries around the world are closer and more frequent. Therefore, it is necessary to strengthen the frequency and intensity of piano communication. Through such activities, we can introduce, promote and promote Chinese piano art to the world, understand Chinese piano culture, and constantly upgrade Chinese piano. The influence of art.

\section{Summary}

In summary, in recent years, under the background of the overall development of cultural undertakings, the achievements of the Chinese piano industry have been obvious to all. The so-called "ten years of trees, a hundred years of tree people", in order to continue this good development momentum, and to make its nationalization development process more advanced, it must be based on nationalized piano education. As a university that plays the main position of Chinese piano talents, it is necessary to have a clear understanding of this, and to actively and effectively change and cultivate more professionals with national responsibility, national style and characteristics. This article also analyzes this purpose in order to play a certain enlightenment and reference role, and believes that with the joint efforts of all people, Chinese piano art will certainly usher in a broader space for development.

\section{References}

[1] Jelena Davidova,Olga Gončarova. Piano Playing Study Process within the Context of Changes in Contemporary Education [J]. Journal of Pedagogy and Psychology "Signum Temporis", 2010, 3(1).

[2] Hatice Onuray Egilmez. Music Education Students' Views Related to the Piano Examination Anxieties and Suggestions for Coping with Students' Performance Anxiety [J]. Procedia - Social and Behavioral Sciences, $2012,46$.

[3] Izzet Yucetoker,Koksal Apaydinli. The Situation and the Importance of Three-Hand Pieces in Piano Education [J]. Procedia - Social and Behavioral Sciences, 2012, 51.

[4] Sirin Akbulut Demirci. Importance of Scales in Piano Education in Turkey [J]. Procedia - Social and Behavioral Sciences, 2012, 46.

[5] Lang LI. Analysis on the Interaction and Integration of Piano Education and Moral Education in Colleges and Universities [J]. Higher Education of Social Science, 2015, 9(5). 